\title{
Caminar, habitar y percibir Espadán. Arte, patrimonio y cultura visual como herramientas didácticas en la reivindicación del paisaje rural y de montaña \\ Walk, inhabit and perceive Espadán. Art, heritage and visual culture as didactic tools in the vindication of rural and mountain landscape
}

Fernando BOLÓS. Universitat de València (España).fernando.chinin@gmail.com

Resumen: A través del estudio de un entorno de montaña, la Sierra de Espadán (Castellón, España), se pretende indagar entre las relaciones que a través del arte, el patrimonio - material e inmaterial-y la cultura visual se generan entre este espacio concreto y el habitante o visitante. Fruto de esas relaciones se pone en valor el entorno y paisaje de montaña, al tiempo que se produce una aproximación cultural al mundo rural.

La idea fuerza es la de utilizar el arte, la educación artística, el patrimonio y la cultura visual como mediadores entre la ciudad y el entorno rural, entre el ambiente urbano y la naturaleza. Se trata de ver cómo estos elementos mediadores refuerzan la percepción del paisaje de montaña desde múltiples ángulos. Desde lo más poético $\neg$ conectado con ideas y conceptos filosóficos-, a lo más pragmático $\neg-$ relacionado con aspectos etnológicos-, pasando por sencillas analogías visuales, no por obvias menos fascinantes.

Se intenta contribuir a una nueva idea de ruralismo, rompiendo con posturas cerradas, prejuicios y clichés establecidos en ambas direcciones: ciudad-campo y campo-ciudad.

Finalmente, el concepto "andar como práctica estética" presenta una forma de tomar conciencia del espacio y apropiarse de él que adquiere una importancia transcendental. Plantea un modo de entender el entorno desde la observación y la experimentación, favoreciendo la creación de vínculos a partir de los que conectar con el paisaje. 
Palabras clave: arte, naturaleza, montaña, patrimonio, caminar, rural

\begin{abstract}
By the study of a mountain environment, Sierra de Espadán (Castellón, Spain), the aim is to explore relationships that through art, heritage -material and immaterial- and visual culture are generated between this particular space and the inhabitant or visitor. The result of these relationships is the value of the mountain environment and landscape, as well as a cultural approach to the rural world is produced.
\end{abstract}

The main idea is to use art, artistic education, heritage and visual culture as intermediaries between the city and the rural environment, between the urban surroundings and nature. It is about seeing how these mediating elements reinforce the perception of the mountain landscape from multiple angles. From the most poetic -connected with ideas and philosophical concepts-, to the most pragmatic -related with ethnological aspects-, going through simple visual analogies, not by obvious less fascinating.

We try to contribute to a new idea of ruralism, breaking with closed positions, prejudices and clichés established in both directions: city-countryside and countryside-city.

Finally, the concept of "walking as an aesthetic practice" presents a way of becoming aware of space and appropriating it, which acquires a transcendental importance. It presents a way to understand the environment from observation and experimentation, favoring the creation of links from which to connect with the landscape.

Keywords: art, nature, mountain, heritage, walk, rural

"El paisaje es el territorio más su imagen cultural, más la figuración que tú añades, el imaginario que le sumas"

Eduardo Martínez de Pisón.

\title{
Introducción
}

Estas palabras que ahora lees no hubieran existido sin la influencia -en diferentes etapas de mi vida- de ciertas lecturas sobre arte, cultura visual y patrimonio, sin ciertos viajes $\neg$ a pie en entornos de montaña $\neg$ y naturaleza o sin horas y horas de escucha de radio sobre asuntos relacionados con los temas del caminar, la sostenibilidad, el arte y la naturaleza. A partir de la acumulación de todas estas experiencias se destilan muchas de las ideas que a continuación se exponen.

Asimismo, son verdaderos detonantes de este texto el pensamiento de Henry David Thoreau (Thoreau, 2013), el descubrimiento del concepto "andar como práctica estética" presentado por Francesco Careri en su Walkscapes (Careri, 2013), o las 
reflexiones de Eduardo Martínez de Pisón en La montaña y el arte (Martínez de Pisón, 2017).

En un mundo globalizado, en el que todo tiende a homogeneizarse, volver la mirada hacia el mundo rural y los entornos naturales que lo rodean se plantea cada vez más necesario para contribuir a mantener espacios, costumbres y tradiciones que forman parte de la idiosincrasia de un lugar y su patrimonio.

Dentro de esta temática, la obra de Sergio del Molino La España vacía (Molino, 2016) parece haber removido conciencias y haber puesto encima de la mesa el tema de la desigual distribución de población entre el mundo rural y el mundo urbano, acentuada en este caso por la singularidad española en la que esta brecha se ve aumentada, generando un mismo concepto de vacío pero en dos sentidos: en el físico $\neg-$ en los entornos rurales alejados de los grandes focos urbanos-y en el psicológico -en la negación o menosprecio de esos entornos en las mentes de quienes provienen de ellos-.

Por consiguiente, la idea de difundir y reivindicar una nueva ruralidad se hace más necesaria que nunca a la hora de luchar contra ese vacío, generando conciencia alrededor de la importancia de la custodia del territorio como concepto relevante, también desde un punto de vista cultural y etnográfico, donde se revela fundamental la relación entre Arte y Naturaleza.

En esta nueva visión del ruralismo debemos entender que lo rural y lo urbano deben convivir con sus diferentes modelos de evolución y desarrollo, estableciendo nexos de comunicación y respeto recíproco. Sólo de este modo podrá establecerse una relación sana y justa.

La selección del concepto de caminar como eje importante de este texto viene motivada, más allá de una inclinación personal por esta actividad, por su significación como actividad empírica que facilita el descubrimiento de las identidades de distintos lugares, la concepción del andar como una forma de tomar conciencia del espacio y apropiarse de él. Ese territorio del que nos vamos a apropiar es la Sierra de Espadán, en el sur de la provincia de Castellón, que se eleva entre los valles de dos ríos para formar un espacio singular y de una belleza extraordinaria.

A pesar de que pueda parecer un territorio relativamente abarcable, cada vez que nos adentramos en él nos ofrece infinidad de novedades y descubrimientos. Hoy en día, que tenemos a nuestro alcance multitud de recursos en forma de mapas, rutas señalizadas o incluso tracks de GPS, es interesante que exista de la posibilidad de dar con hechos que nos sorprendan.

A través del uso del patrimonio - material e inmaterial-, del arte y de la cultura visual se pretende poner en valor la riqueza de la Sierra de Espadán y de las posibilidades 
que nos ofrece para generar una conciencia respetuosa con el medio ambiente, el mundo rural y el paisaje de montaña.

La aproximación a la sierra no debe hacerse sólo desde un interés físico -como mero accidente geográfico-, económico -desde los recursos que allí se aprovechan-, deportivo -en verdadero auge en las últimas décadas-o de ocio -como un lugar donde escapar del ruido y la vorágine de nuestro día a día-. A menudo, estas formas de acercarse a este entorno precisan de mayor profundidad. Por ello, si a estos modos de aproximación añadimos el componente cultural vinculado al territorio, podremos conseguir que se llegue a entender el lugar y valorarlo. Sólo así lograremos estimarlo y preservarlo, haciendo servir la emoción como vehículo de aprendizaje en el único camino posible: la educación.

\section{Espadán}

Geografía fisica y humana en el entorno del Parque Natural de la Sierra de Espadán

\section{Principales áreas del Parque Natural de la Sierra de Espadán}

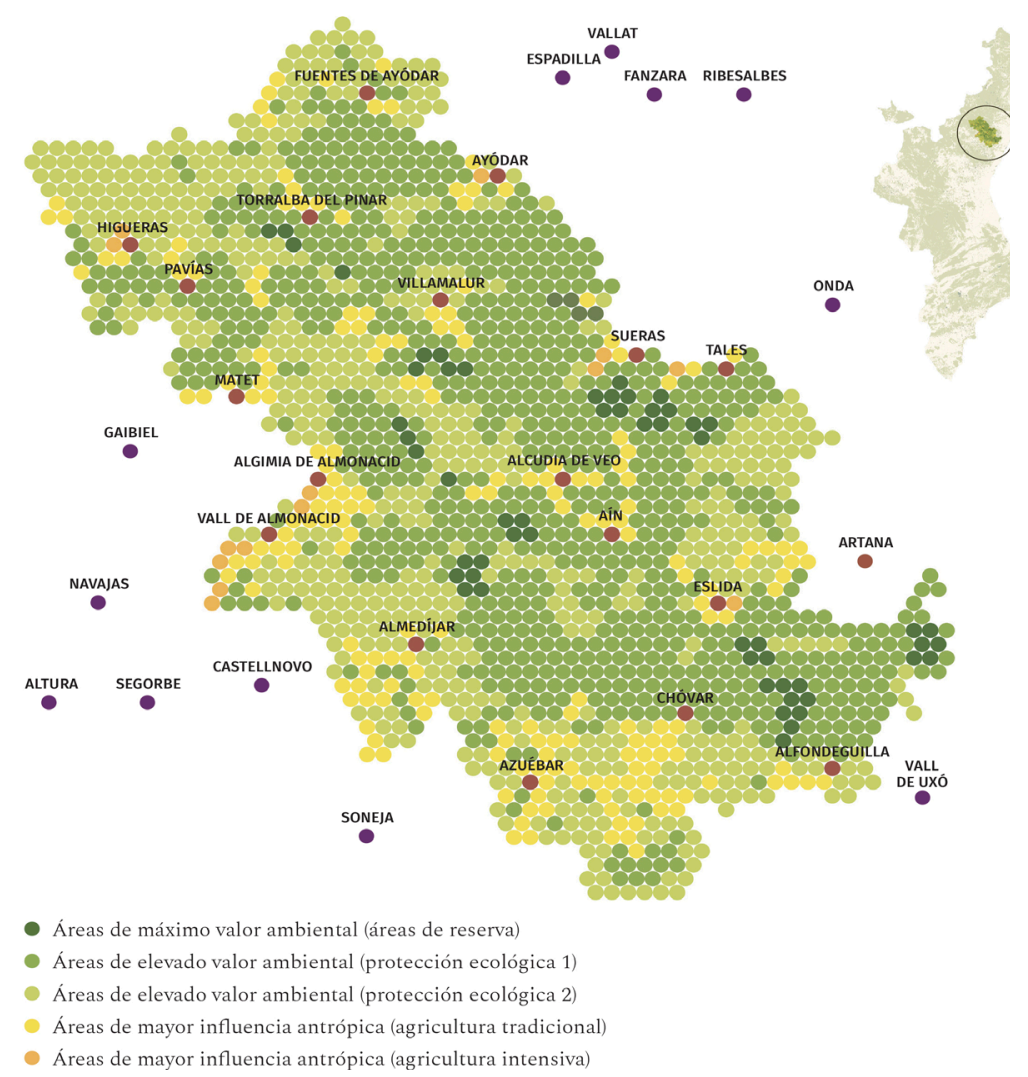

Figura 1. Mapa de áreas del Parque Natural de la Sierra de Espadán. (Fernando Bolós, 2018). ${ }^{1}$

\footnotetext{
1. Ilustración realizada a partir de los datos extraídos de la Memoria de Gestión 2015 del Parque Natural de la Sierra de Espadán y de la página web de Parques Naturales de la Generalitat Valenciana (http://www.parquesnaturales.gva.es/es/web/pn-serra-d-espada).
} 


\section{Geografía física}

La Sierra de Espadán está situada entre las cuencas del río Palancia y del río Mijares, en la provincia de Castellón, un territorio montañoso ubicado en las últimas estribaciones del Sistema Ibérico en su aproximación hacia el mar Mediterráneo². Es un espacio geográfico situado en las comarcas castellonenses del Alto Palancia, el Alto Mijares y la Plana Baixa. Fue declarada Parque Natural de la Sierra de Espadán el 29 de septiembre de 1998, siendo el segundo espacio protegido más extenso de la Comunidad Valenciana, con una extensión de algo más de 31.000 hectáreas.

Esta sierra conforma un relieve abrupto y quebrado. Cimas, cordales, valles, barrancos, ramblas y fuentes entre los que destacan, tanto por su singularidad como por su buen estado de conservación, los frondosos bosques de alcornoques, algunos de los más singulares de la Comunidad Valenciana. El alcornoque posee la peculiaridad de ofrecer resistencia al fuego, lo que le dota de un gran valor ecológico. Estas características le confieren un excepcional valor paisajístico y una riqueza botánica y faunística excepcionales.

\section{Geografía humana}

La utilización de los recursos y las actividades respetuosas con el medio ambiente que se han desarrollado en este territorio han ido, a lo largo de los años, modelando y dándole forma a los diferentes paisajes que hoy podemos apreciar en la Sierra de Espadán, reflejo de la estrecha relación de sus habitantes con la sierra.

El aprovechamiento de los recursos naturales ha sido la base de muchas de las actividades económicas que se han desarrollado en su entorno, tanto a nivel agrícola como industrial.

La huella industrial de las actividades económicas desarrolladas en este entorno en distintas épocas se puede apreciar a través de numerosos elementos de la propia sierra. Desde las neveras, hasta las plantas embotelladoras de agua, pasando por las carboneras, las numerosas minas de la Sierra (Chóvar, Aín, Torralba...), la leña para las cercanas industrias cerámicas o del yeso y, de manera especial, las industrias del corcho.

\footnotetext{
2. La licencia de incluir el Paraje Natural Municipal de La Dehesa de Soneja, un pequeño territorio anexo al parque natural de la Sierra de Espadán, como elemento de la misma viene motivada por dos razones de distinta índole. En primer lugar, porque es un paraje protegido unido físicamente al margen del parque natural y ostenta características geográficas, etnológicas y culturales análogas a Espadán. En segundo lugar, porque en varias publicaciones relativas a la Sierra de Espadán aparece como parte de la misma. El hecho de incluir este espacio nos permite, además de resaltar su singularidad, ampliar las conexiones entre ciertos elementos del entorno.
} 
La misma explotación de los alcornocales para la extracción de corcho entronca con la explotación agrícola del entorno, que se complementa con otros productos de la sierra como son la miel, el aceite, la almendra, la algarroba o las cerezas.

\section{Espadán}

Más allá de estos datos, Espadán es el parque natural, pero no sólo. Espadán, como concepto transciende el territorio acotado del parque y va más allá, formando parte importante de la cultura y de la vida del entorno que rodea a la sierra. En palabras de Luis Gispert Macián, ilustre e incansable viajero conocedor de cada rincón de esta sierra,

Los pueblos de Espadán forman parte de ese interesante y bucólico mundo donde el ruido no se conoce, ni tampoco el desmesurado ocio y la vorágine propia de las grandes urbes. Todos ellos cuentan con un patrimonio natural, etnográfico y cultural como máximo exponente. (Gispert, 2003, p. 23)

Y todo ese patrimonio está ahí, aguardando a que lo sepamos apreciar y proteger. Un regalo para nuestros sentidos.

\section{Percibir}

La cultura visual como fundamento para la comprensión de la montaña

\section{Una aproximación estética a la montaña}

Como se puede desprender de La montaña y el arte (Martínez de Pisón, 2017), una persona es mejor montañero después de conocer la parte cultural y artística de la montaña y puede apreciar en mayor medida el arte después de conocer la montaña. Su modo de entender cómo aproximarse a la montaña en sumamente interesante. El catedrático Martínez de Pisón afirma,

Somos partidarios de dejar las montañas altas y silvestres como dominios de la naturaleza, donde sea necesaria una relación con los rasgos acentuados de los paisajes agrestes, donde perdure el encuentro con la soledad y sean necesarios esfuerzo y complicidad con el medio, donde se mantenga la belleza del paisaje intacto, grande, fuerte y resistente, que te obligue a una inmersión en él y donde obtengas, en suma, una experiencia vital excelente. (Martínez de Pisón, 2017, p. 92)

En relación con el auge romántico del concepto de lo sublime, la aproximación a la montaña siempre nos deja una concepción de belleza salvaje que nos hace sentirnos apenas una mota en la inmensidad del universo. Y ésa pequeñez nos vincula al significado de lo sublime como aquello que por su magnitud o carácter está por encima de todo, despertando por igual sentimientos de desasosiego y atracción. Joseph Addison fue el primero en teorizar sobre lo sublime, destacando la grandeza como una de las causas más poderosas que excitan a nuestra imaginación. Más tarde Burke 
le da al término un carácter más aterrador y violento, relacionado con la sensación de nimiedad que produce lo que es grande y sublime en la naturaleza, causando un estado del alma que contiene cierto grado de horror. (Ramírez, 1997, p. 105)

Ambas concepciones de lo sublime las encontramos en Espadán. Basta con establecer analogías visuales entre ciertos espacios y algunas de las obras más conocidas del artista romántico Caspar David Friedrich para comprobarlo. Podemos elevarnos en una cumbre en un día cubierto para sentirnos El caminante frente al mar de niebla (h. 1818) apreciando esa grandeza e inmensidad que nos ofrece el paisaje. Igualmente, podemos adentrarnos en la penumbra de un poblado bosque de alcornoques o enfrentarnos a la soledad y desazón que se experimenta en las ruinas del despoblado del Jinquer ${ }^{3}$ para hallarse en Abadía en un robledal (1809-1810).

Con la correspondencia entre estas dos obras del Romanticismo y los diversos espacios que podemos encontrar en la sierra comprobamos la presencia de esa imagen cultural de la montaña. Y para contemplarla es necesario, como ya hicieran los artistas románticos y como sugiere Eduardo Martínez de Pisón, adentrarse en ella con ojos de explorador, buscando espacios agrestes, parajes inaccesibles y rincones solitarios.

No pretendo establecer esta comparación y circunscribirla sólo a este artista o a estas dos obras, y mucho menos sólo al ámbito del Romanticismo. Es más, si por ejemplo profundizáramos en el interés romántico por la ruina, Espadán sería una auténtica cantera de poderosas imágenes. Pero mi intención sólo es la de remarcar cómo en el ámbito natural y en el paisaje de montaña podemos encontrar un vasto campo de relaciones entre el territorio -y su paisaje- y el arte.

\section{La montaña como entorno cambiante}

Más allá de la manifestación pictórica del concepto de lo sublime, se puede ampliar esta relación entre el entorno natural y las artes visuales desde uno de los conceptos más interesantes y de mayor importancia en la montaña: la mutabilidad. Como entono, la montaña es un espacio cambiante, variable, alterable e inestable, bien sea por la acción del ser humano, de la propia naturaleza o de las distintas condiciones que intervienen en la percepción misma del entorno. En resumen, nunca la percibimos de la misma manera.

Este hecho es algo que se puede relacionar con la reflexión que hace Elliot W. Eisner en el prólogo del libro de Rudolf Arnheim Consideraciones sobre la educación artística,

\footnotetext{
3. Pedanía de Alcudia de Veo abandonada durante la Guerra Civil.
} 
El mundo que experimentamos directamente es un mundo en estado de cambio. Los objetos se mueven, la calidad y la luz del día cambian, nuestra posición respecto a lo que contemplamos nunca es exactamente la misma. Los seres humanos tienen la capacidad de destilar de este flujo las características esenciales de un campo, y al hacerlo le dan constancia. (Arnheim, 1989, p. 17)

El uso del arte como mediador para asimilar este concepto de un entorno en constante cambio es muy valioso. Por ejemplo, en el caso de la luz y sus distintos grados de incidencia en el paisaje natural se establece de manera ágil una relación evidente con el Impresionismo.

Esa conexión con el Impresionismo nos guía hasta la obra de Monet, quien desarrolló una técnica rápida para captar la imagen perceptiva, que no puede durar más que unos segundos, logrando registrar las diferentes impresiones visuales que ésta produce. Un claro ejemplo de esa comprensión de cómo incide la luz sobre un mismo elemento es su serie sobre la Catedral de Rouen.

Registrar los cambios que se dan en el paisaje a causa de la distinta incidencia de la luz, de las estaciones o de las condiciones meteorológicas y climáticas, puede ser una tarea fascinante, pues en el entorno natural se aprecia sobremanera.

Este hecho refuerza la idea de Espadán como un entorno vivo, en movimiento, en constante cambio y evolución. Un verdadero regalo para los sentidos ya que cada aproximación, cada inmersión en sus espacios acaba siendo singular y única, personal e intransferible.
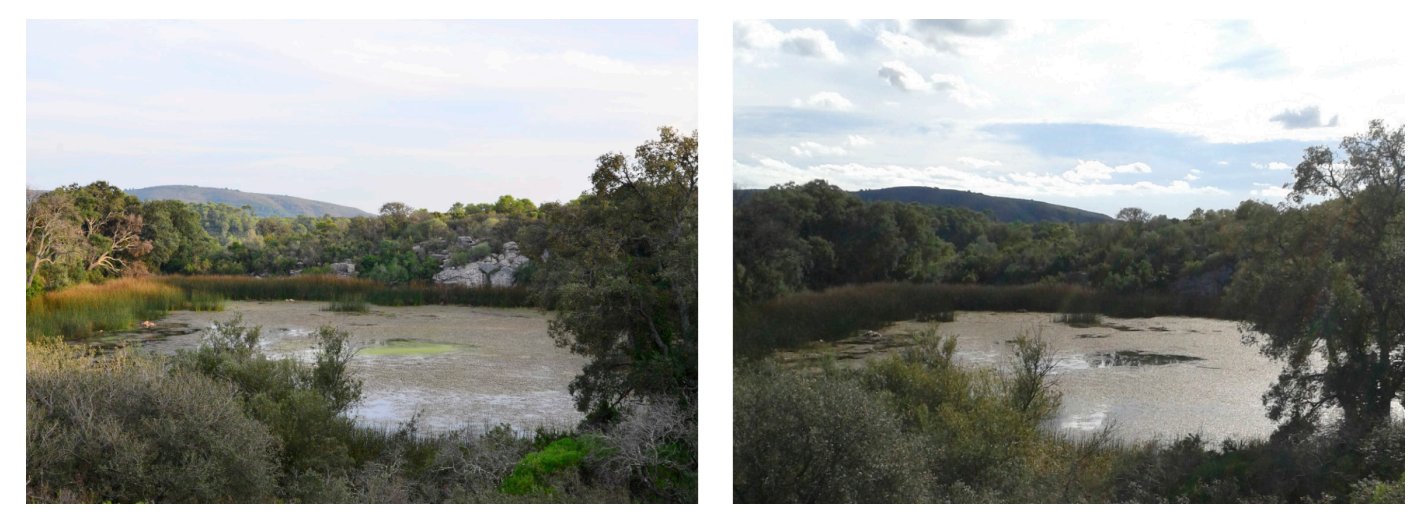

Figura 2. La laguna del paraje de la Dehesa de Soneja como ejemplo de entorno cambiante en apenas un mes de diferencia: octubre (Luis Miguel Blay Campos, 2013) y noviembre (Fernando Bolós Doñate, 2013).

\section{Perfiles que se recortan contra el cielo}

Siguiendo con otra idea expuesta por Eisner al prologar Consideraciones sobre la educación artística de Arnheim, tratamos la relación que se establece entre diferenciación y generalización, lo que constituye una importante paradoja, 
En cierto sentido la percepción es un proceso paradójico. Por otra parte, el reconocimiento exige que diferenciemos suficientemente para poder identificar a personas, lugares y objetos que son significativos para nosotros. (...) Es decir, hemos de reconocer la unicidad y la comunidad de forma prácticamente simultánea. (Arnheim, 1989, p. 17)

Esto pasa, por ejemplo, al intentar memorizar e interiorizar los perfiles de las montañas, tomar referencias y aprender a situarnos y orientarnos en el territorio. Cuando nos situamos frente a un skyline con una sucesión de montañas, todas las cimas pueden parecernos a priori iguales o similares.

Por eso debemos ser capaces de identificar formalmente cada pico y, además, percibirlos como un conjunto. En el entorno natural este apoyo visual nos puede ayudar a tomar referencias y aprender a situarnos y orientarnos en el territorio.

Como referencia artística contemporánea podemos tomar un recurso utilizado por Hamish Fulton en alguna de sus obras e interiorizar el perfil que se recorta contra el cielo. Esto nos ayudará a distinguir unas montañas de otras a la vez que comprendemos en conjunto la silueta de la sierra desde una ubicación concreta.

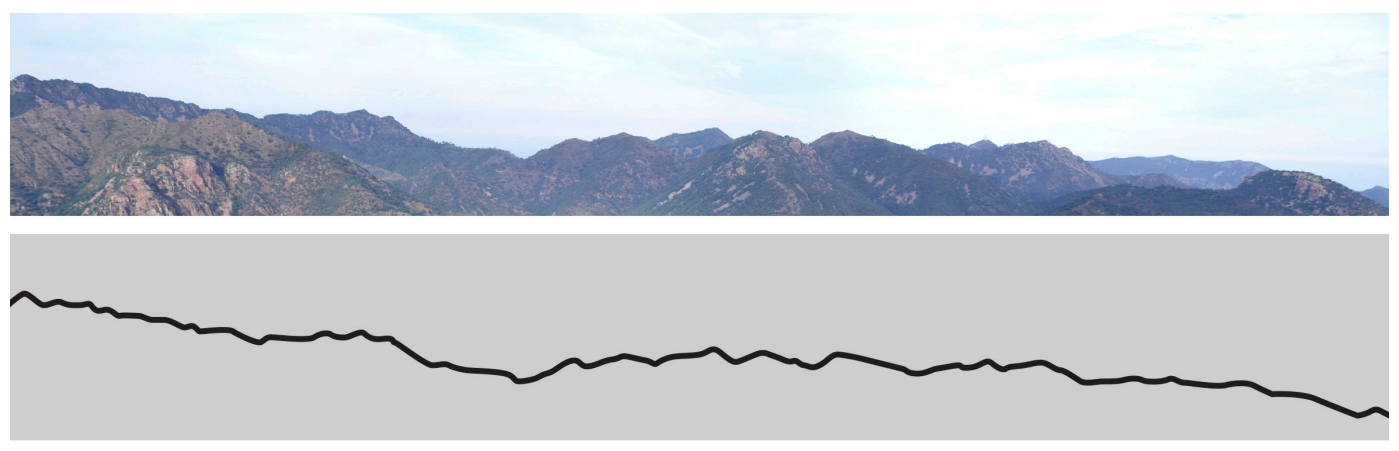

Figura 3. Perfil de la Sierra de Espadán (Luis Miguel Blay Campos, 2018) y recreación de las obras de Hamish Fulton a partir de la imagen anterior (Fernando Bolós, 2019).

\section{Habitar}

Habitar lo deshabitado

Encontrarse en Espadán es, en muchas ocasiones hallar huellas de un pasado desaparecido que sin embargo forma parte importante de su identidad. Una identidad que se proyecta en el futuro y aspira a preservar su espacio de desarrollo.

Lo deshabitado pretende hacer aquí referencia a dos ideas. La primera, en un sentido literal, es la de las innumerables construcciones que aparecen en estado de abandono en la sierra. La segunda, en un sentido más figurado, es la de lo deshabitado como la despoblación que sufre el mundo rural. Lo deshabitado es por tanto una amenaza, pero si cambiamos el punto de vista, también es una nueva oportunidad para poner en valor y redefinir fórmulas para habitar el mundo rural. 
Me resisto a creer que el ruralismo es un modo de vida que ha llegado a su fin, ya que veo en él inmensas oportunidades. Otra cosa es pretender la evolución del mundo rural bajo las mismas premisas que el urbano sin pararse a pensar que ambos tienen contextos distintos y que cada uno tiene su propia idiosincrasia. Son modelos que se pueden nutrir mutuamente y que pueden cohabitar en perfecta armonía.

\section{Aliados en el entorno de la sierra de Espadán}

Reivindicar el medio rural, la etnología, la historia y la identidad propias de las tierras de Espadán es una tarea que precisa de entidades vinculadas al territorio que propongan diálogos con el entorno a través del arte, la educación artística, el patrimonio material e inmaterial y la cultura visual. Estos organismos son principalmente museos de toda índole, aunque también pueden acometer esta tarea otras instituciones con una marcada naturaleza didáctica o cultural.

Esta aproximación cultural al mundo rural y al mundo de la montaña se debe llevar a cabo a través de canales de mediación entre el entorno y el morador-ocasional o permanente- de Espadán.

Los museos tienen una función capital en la compleja relación entre paisajes e identidades dada la conexión con su entorno, estrechamente vinculada al patrimonio material e inmaterial. La comunidad adquiere la responsabilidad individual y colectiva de proteger y defender los paisajes culturales que forman parte activa de la idiosincrasia del lugar.

Dentro del entono de la sierra de Espadán encontramos innumerables huellas etnológicas de las que el Centro de Visitantes, en la localidad de Eslida, hace una interesante recopilación. En él podemos hacer un recorrido por los aspectos naturales y etnológicos de la sierra así como un recorrido visual por las singularidades de cada uno de los 19 pueblos cuyo término está dentro del parque natural. Estrechamente unida a la huella etnológica se encuentra la industrial: desde el aprovechamiento del corcho de sus alcornocales, ejemplo de gestión sostenible, hasta las relaciones con las industrias cercanas a la sierra, a las que en tiempos pasados proporcionaba energía, como podemos apreciar en el Museo del Yeso de Soneja o en el Museu del Taulell 'Manolo Safont' de Onda. Este último, en un edificio en perfecta relación visual con el entorno de Espadán, parece dialogar con la sierra. Ese diálogo, vinculado al pasado, lo podemos apreciar en su colección etnográfica y su implicación en la recuperación de la memoria y el acervo cultural.

Siguiendo ahora las pistas de la huella agrícola damos con el Museo del Aceite de Segorbe, un pequeño espacio con una museografía excelente, accesible a todo tipo de públicos, que ahonda en las raíces del cultivo milenario de la aceituna en estas tierras. Su visita nos permite comprender la laboriosidad de los trabajos del campo 
$\mathrm{y}$, por similitud, nos acerca a una cierta idea de cómo se trabajan el resto de cultivos serranos.

En el aspecto histórico, destaca la Guerra Civil y los innumerables vestigios de la contienda que quedan en la sierra, desde el despoblado del Jinquer (abandonado en 1937) hasta el Mas de la Campana de Sueras (cuya famosa campana no es más que la cabeza vaciada de un obús con la inscripción "Viva el Humor"), pasando por las innumerables barreras defensivas de la línea XYZ utilizada en la Batalla de Levante, en julio de 1938. Todas estas huellas, podemos también relacionarlas con la Fundación Max Aub, en Segorbe. Aub fue una figura clave de la resistencia desde el ámbito cultural, quedando su vida y obra marcadas significativamente por el transcurso de la guerra.

Sorprendentemente, la última huella que ha aparecido en el entorno ha sido la de la cultura urbana, a través del MIAU (Museo Inacabado de Arte Urbano) de Fanzara, un proyecto sumamente interesante por la capacidad de trasladar una cultura visual propia del mundo urbano al medio rural y de convertir a los habitantes de Fanzara en verdaderos mediadores entre la obra y los visitantes. Un proyecto en el que la implicación de los menos de 300 residentes de este municipio es capital, ya que las propias casas de los vecinos se convierten en residencias de artistas durante el festival, que se celebra anualmente a principios de julio. Un claro ejemplo de cómo pueden establecerse diálogos entre mundo urbano y mundo rural.

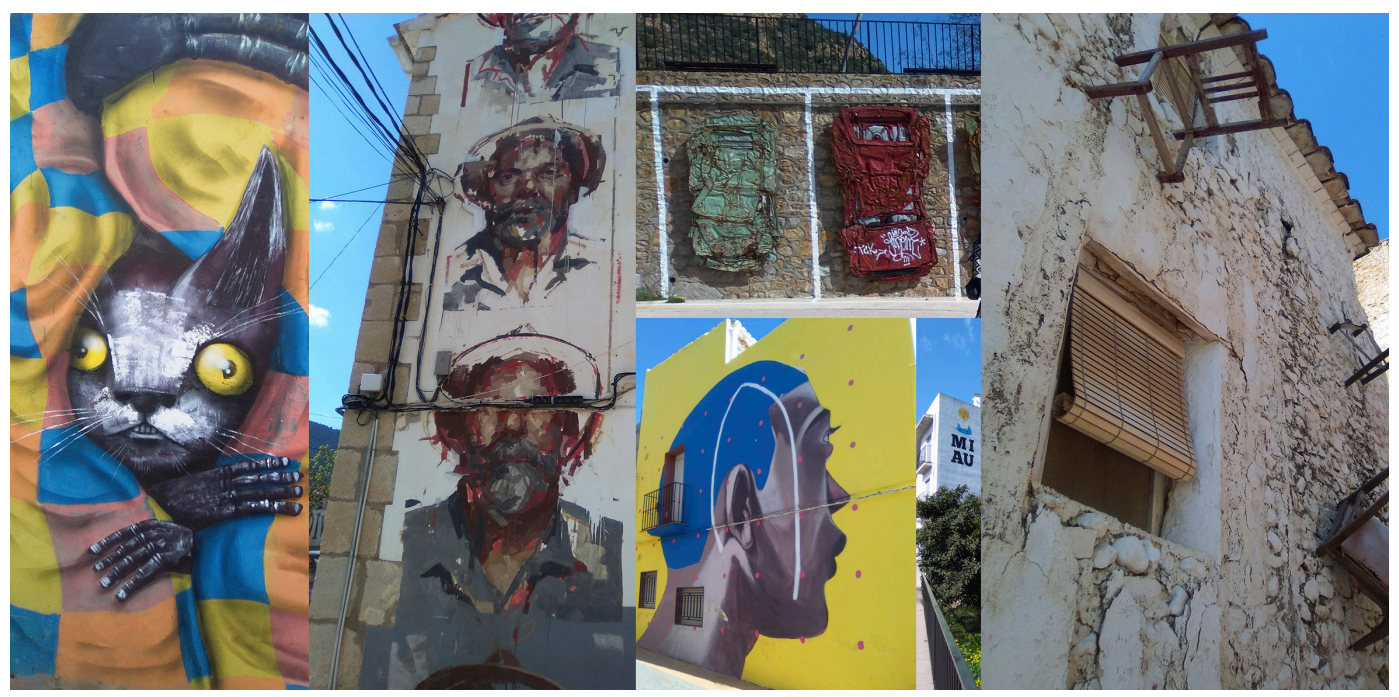

Figura 4. Varias obras del MIAU de Fanzara (Fernando Bolós, 2017).

\section{Bosquera, geografía e historias de un lugar}

También una manifestación artística puede convertirse en un aliado fundamental para elevar el valor de un entorno natural y evocar la estima, el respeto y la vinculación a un territorio. Es el caso de Bosquera, un proyecto del artista afincado en Valencia Juanma Pérez, 
Es un libro, editado por Bandàparte (Pérez, 2017)y una exposición, producida por la Universidad de Valencia, aunque en lo personal fue algo más. Fue inspirador de este proyecto además H. D. Thoreau, como puedes haber adivinado, que como seguro que sabes también tiene amplias reflexiones sobre la relación entre el hombre y la naturaleza. (J. Pérez, comunicación personal, 6 de junio de 2018)

El proyecto está impregnado de amor por el territorio y aporta una sensación de paz y sosiego que parece, para quien conoce el paraje de Mosquera-aquí un espacio que parece estar en otro nivel de realidad llamado Bosquera-, transportarnos un siglo atrás e imaginarnos inmersos en la vida en el valle, con el sosiego que Martín Castro, el protagonista de la historia, describe.

Como nombra Javier Alcoriza en uno de los textos del mismo libro, las relaciones que establecemos con el personaje nos llevan a pensar en un waldense en Espadán. (Alcoriza, 2017)

Establece un juego de relaciones en el que lo real y lo ficticio se confunden y, la verdad, viene a importarnos bien poco. Porque al fin y al cabo Bosquera es un viaje al interior del bosque, es un paseo entre alcornoques, es comprender la dura vida de los pastores y las gentes del campo de principios del siglo XX. Es, sin más, la evocación profunda a la historia y la naturaleza de un lugar.

Como afirma Pablo Vidal González en este libro, Martín Castro, nuestro protagonista, cerró un ciclo de un año en el corazón de la Sierra de Espadán, acompañado de todos los agentes, humanos y naturales, que modifican y transforman el paisaje, gracias a los que nos podemos maravillar al volver a este entorno tan especial y mágico. (Vidal González, 2017)

A través de sus escritos, dibujos y fotografías nuestro protagonista nos deja rastro de sus pasos, seguidos muy de cerca por el propio autor, que un siglo después recrea sus mismas sensaciones y expresa las suyas propias a través de cuadros y fotografías. Mención aparte merecen los objetos encontrados cuya autoría se atribuye a nuestro protagonista, constituyendo una verdadera muestra de ready-made.

Una aventura en la que, gracias a los mapas de los itinerarios seguidos tanto por Martín Castro como por Juanma Pérez, podemos revivir las sensaciones de nuestro personaje y generar nuestro propio Bosquera. Eso sí, siempre paseando alrededor del entorno de Mosquera, en un juego de heteronimia natural que no logramos saber si es real o ficticio. Aunque en realidad poco importa cuando de lo que se trata es de sentirlo.

\section{Caminar}

Siguiendo las huellas culturales en el territorio de Espadán 
BOLÓs / Caminar, habitar y percibir Espadán. Arte, patrimonio y cultura visual como herramientas didácticas en la reivindicación del paisaje rural y de montaña

\section{Un sencillo y eficaz sistema visual}

Un espacio como un parque natural, recorrido de uno a otro costado por pistas, caminos, senderos y veredas, está repleto de ciertos elementos visuales que nos pueden ayudar a orientarnos y a dirigir nuestros pasos. La red de senderos homologados, mediante sencillos códigos visuales y cromáticos establece un sistema simple y accesible para la práctica senderista y la orientación con seguridad, calidad e información de la gran mayoría de usuarios. Este sistema visual fomenta la inmersión en el entorno natural como una actividad enriquecedora, respetuosa con el medio y su cultura. Un recurso didáctico que proporciona una información esencial para la movilidad y orientación del transeúnte, facilita la práctica del senderismo como modo de aprehender los paisajes de montaña y propicia el placer de caminar sin rumbo, una experiencia errática que genera una confortable sensación de desprendimiento.

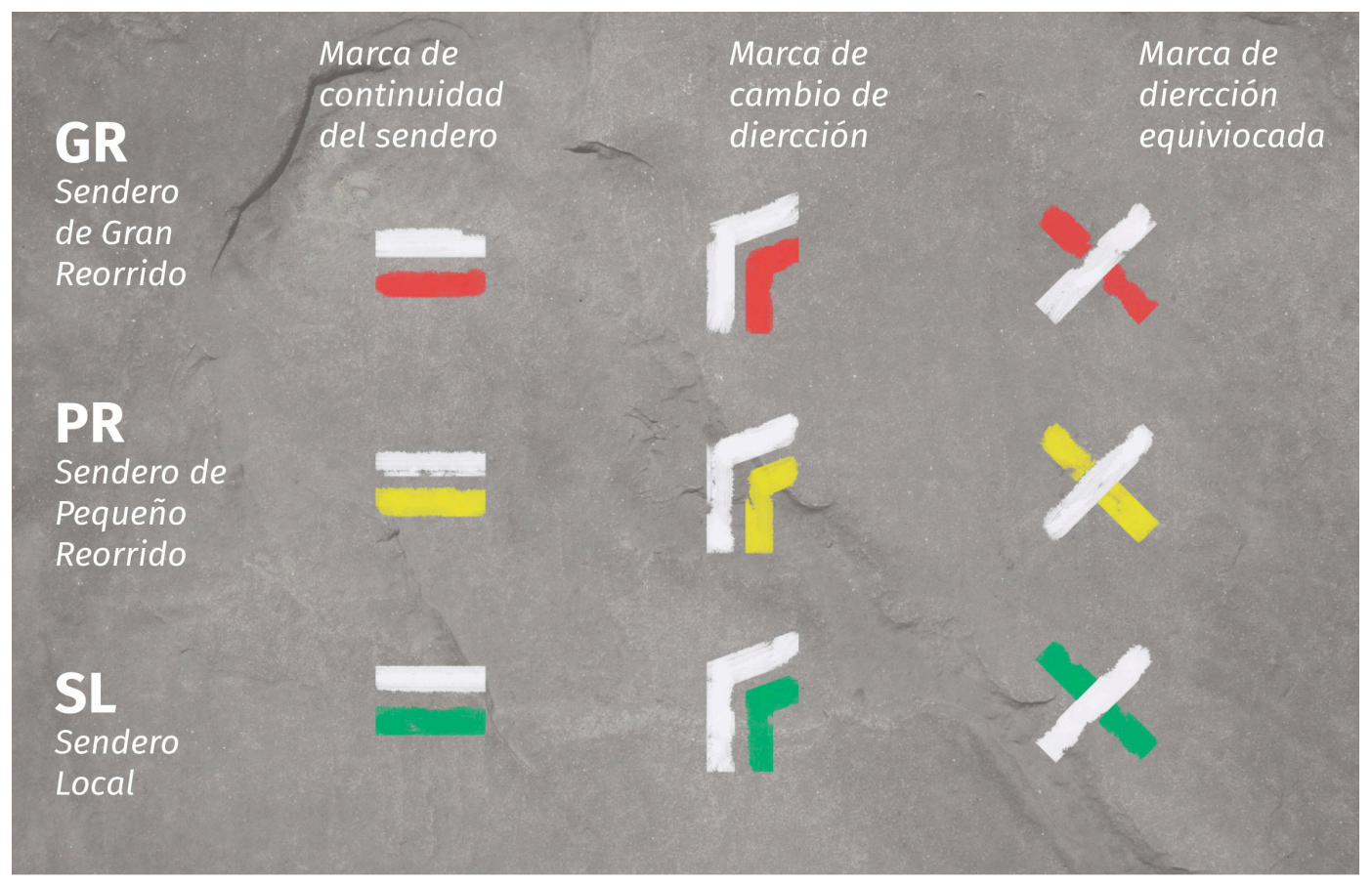

Figura 5. Infografía sobre la señalización de senderos de la Federación Española de Deportes de Montaña y Escalada (Fernando Bolós, 2019).

\section{Caminar como práctica estética}

Una vez hemos asimilado cómo las señales visuales nos pueden aportar seguridad y garantía en el aspecto más prosaico del desarrollo de nuestros itinerarios, nos elevaremos a un estado más lírico del hecho de caminar.

En el desarrollo de este tema ha tenido una influencia más que notable, como se puede entender, el libro de Francesco Careri Walkscapes, el andar como práctica 
estética que hace una indagación histórica del concepto de andar como medio de aproximarse al territorio y apropiarse de él. (Careri, 2013)

Pero también he bebido de otras fuentes que prestan atención al hecho de los afectos hacia un lugar, lo que me ha permitido hallar reflexiones interesantes acerca de este asunto. En Fuera del Mapa, Alastair Bonnett nos convence de que nos hemos vuelto mucho más expertos en destruir lugares que en construirlos y que el amor al lugar puede llegar a ser considerado como algo anticuado o reaccionario. Sin embargo, el hecho de que los lugares sean indistinguibles de una a otra punta del mundo no resulta satisfactorio ni intelectual ni emocionalmente. (Bonnett, 2016)

Es precisamente frente a ese hecho de los lugares desprovistos de personalidad e identidad frente al que quiero contrastar y evidenciar la autenticidad de un espacio como Espadán. Un espacio que, además se entiende mejor cuando se está en él, dejando que el tiempo corra a otro ritmo.

Un lugar en el que nos podemos impregnar de su cultura, su historia y su patrimonio $\mathrm{y}$, siguiendo los rastros de las huellas industriales, etnológicas, agrícolas o de la historia, recorrer la práctica totalidad de su territorio a pie relacionando patrimonio y entorno.

Como se puede apreciar en el siguiente mapa se han establecido perímetros alrededor de los elementos patrimoniales más importantes. Estas áreas tienen aproximadamente $2 \mathrm{~km}$ de diámetro, por lo que, si lo observamos con detenimiento, comprobaremos que en la práctica totalidad de los itinerarios que establezcamos para adentrarnos en la montaña estaremos en contacto con huellas patrimoniales y culturales. 


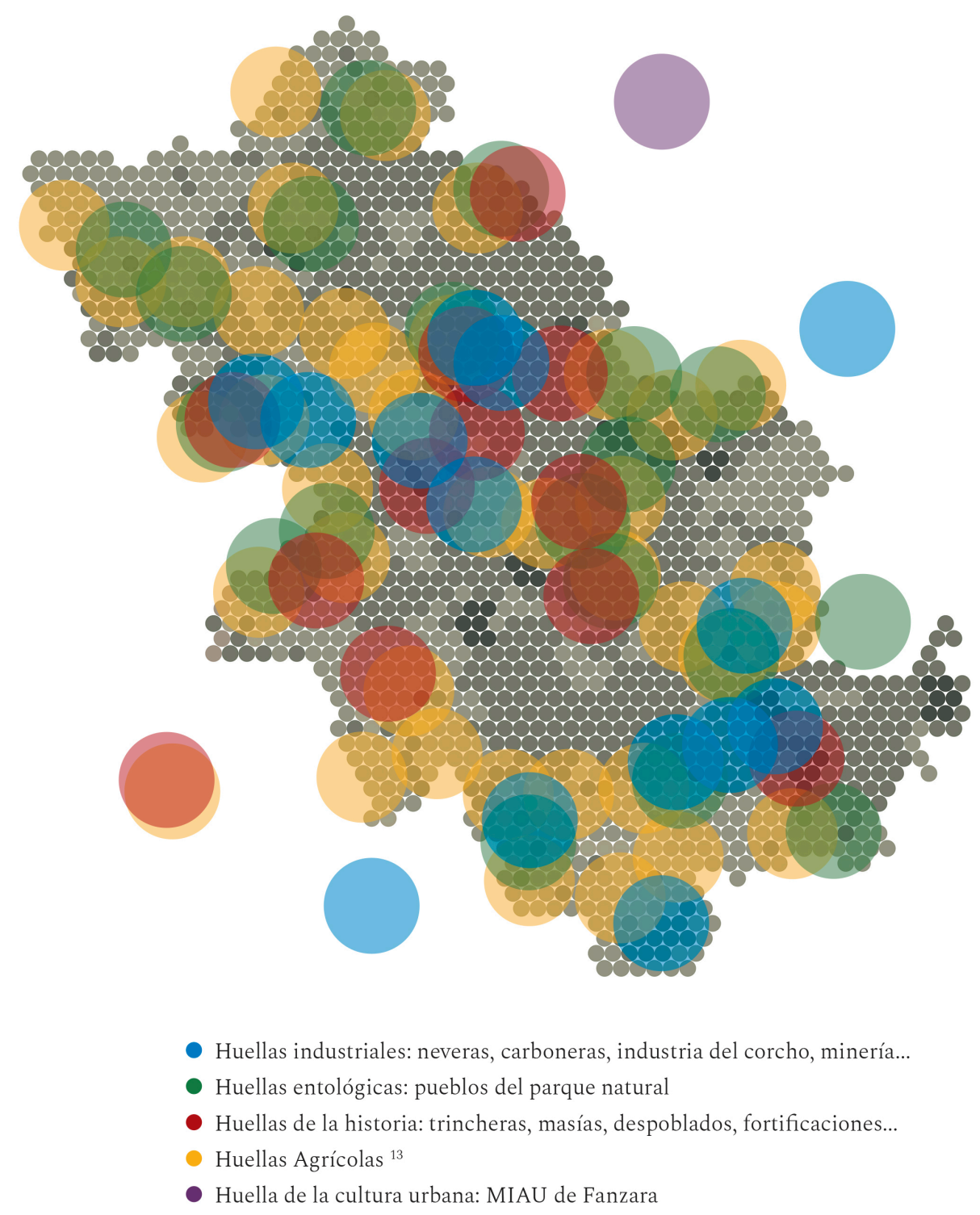

Figura 6. Infografía de la ubicación de las principales huellas patrimoniales de la Sierra de Espadán (Fernando Bolós, 2019).

De este modo, la inmersión en la sierra será una fuente de conocimiento del mundo que nos rodea. El hecho de andar será una forma de transformación del paisaje y del propio caminante, una acción simbólica de adueñarse del entorno al mismo tiempo que te diluyes en él. Tú lo haces un poco más tuyo. Él te hace un poco más suyo.

Uno de los conceptos más potentes que expone la obra de Careri es,

El walkabout -palabra intraducible, solo comprensible en el sentido literario de "andar sobre" o "andar alrededor"- es el sistema de recorridos a través del cual los pueblos de Australia han cartografiado la totalidad del continente. Cada montaña, cada río y cada pozo pertenecen a un conjunto de historias/recorridos -las vías de 
los cánticos- que entrelazándose constantemente, forman una única «historia del tiempo del Sueño“, que es la historia de los orígenes de la humanidad. (2013, p. 32)

Así pues, abrazo esa idea de cartografiar un espacio a través de un sistema de historias/recorridos unidos a la cultura del territorio.

Pero si a alguien hemos de volver en este libro es alrededor de Fulton que,

Elabora el tema del andar como un acto de celebración del paisaje no contaminado, una especie de peregrinación ritual a través de los restos de la naturaleza. Su trabajo va acompañado por una preocupación ambiental y ecológica, y sus viajes pueden leerse incluso como una forma de protesta. (Careri, 2013, p. 122)

Esta concepción de la práctica del andar coincide con la visión que en este texto se le pretende otorgar al caminar, adentrándose en la naturaleza y entrando en comunión con ella. Una nueva forma de profunda espiritualidad que nos conecta con los aspectos más esenciales de la vida.

\section{Caminar, detenerse y volver a caminar}

Pero además de andar, también me interesa el concepto de detenerse, de bajar el ritmo, de acondicionar los procesos vitales (y por añadidura los intelectuales, culturales y artísticos) a un modo de entender la vida con más reposo y más reflexión, huyendo de la inmediatez y el "cortoplacismo" y buscando metas a medio-largo plazo que consoliden un nuevo modelo de convivencia entre el habitante y su entorno.

Así lo advierte Careri en el texto Walkescapes ten years after que cierra la reedición del libro en su décimo aniversario,

Este primer acto revolucionario de paz estaba vinculado al andar y al detenerse. $\mathrm{Al}$ arte del errar le sigue el arte de los encuentros, el arte de la construcción de un espacio de umbral, del establecimiento de una frontera más allá del Espacio y del Tiempo, donde poder afrontar el conflicto con lo diverso con un saludo de no beligerancia. (Careri, 2013, p. 167)

Es precisamente el acto de detenerse el que posibilita el encuentro con el diferente en un espacio común. Se trata de caminar para converger con el otro y generar diálogos que enriquezcan el discurso.

Así pues, al caminar también es transcendental tomar el tiempo necesario para entender el contexto, detenerse y asimilar toda la carga emocional que nos proporciona el entorno y sus moradores. Sólo así podremos reflexionar acerca del espacio en el que nos movemos.

Siempre es necesario pararse, observar y aprender para poder volver a caminar en busca de nuestros siguientes pasos. 


\section{Conclusión}

Desde la conciencia de que queda mucho camino por recorrer, especialmente explorando las relaciones del arte y la creación contemporánea con el paisaje rural y de montaña, sirvan estas últimas palabras para intentar esbozar sucesivas vías que explorar. Se trata, apenas, de establecer unas directrices que nos invitarán a seguir profundizando en el tema que nos ocupa: en las relaciones de los museos locales con su entorno, en las relaciones entre arte y naturaleza con el CDAN ${ }^{4}$ como clara referencia, en ideas singulares y atractivas como el caso del proyecto educativo de la Real Fabrica de l'Alcora, en la figura del ecomuseo como factor alentador del aprecio al entorno o en proyectos cooperativos en relación con la cultura visual y el patrimonio - a través del crowdfunding- para divulgar el entorno de la Sierra de Espadán. Hacia allí dirigimos nuestros próximos pasos.

\section{Referencias}

Alcoriza, J. (2017). El waldense de Espadán. En J. Pérez, Bosquera (pp. 63-69). Córdoba: Bandaàparte Editores.

Argan, G. C. (1991) El Arte moderno: Del iluminismo a los movimientos contemporáneos. Madrid: Akal.

Arnheim, R. (1993). Consideraciones sobre la educación artística. Barcelona: Ediciones Paidós.

Bonnett, A. (2017). Fuera del mapa. Barcelona: Blackie Books.

Careri, F. (2013), Walkscapes: el andar como práctica estética. Barcelona: Gustavo Gili.

Gispert Maciá, L. (2003). De excursión por el Alto Palancia: 37 rutas a pie. Segorbe: Ayto. de Segorbe.

Martínez de Pisón, E. (2017). La montaña y el arte. Madrid: Fórcola Ediciones.

Molino, S. del. (2016). La España vacía: Viaje por un lugar que nunca fue. Madrid: Turner.

4. CDAN, Centro de Arte y Naturaleza, espacio museístico situado en Huesca dedicado a las relaciones entre arte contemporáneo, naturaleza y paisaje. 
BOLÓs / Caminar, habitar y percibir Espadán. Arte, patrimonio y cultura visual como herramientas didácticas en la reivindicación del paisaje rural y de montaña

Pérez, J. (2017). Bosquera. Córdoba: Bandaàparte Editores.

Ramírez, J. A. et al. (1997). Historia del Arte: El mundo contemporáneo (7 ed.). Madrid: Alianza.

Thoreau, H. D. (2013). Walden. Madrid: Errata Naturae.

Vidal González, P. (2017). El universo de Martín Castro y Mosquera. En J. Pérez, Bosquera (pp. 5-11). Córdoba: Bandaàparte Editores. 